\title{
Socio-economic inequalities in malnutrition among children and adolescents in Colombia: the role of individual-, household- and community-level characteristics
}

\author{
Sandra Garcia ${ }^{1, *}$, Olga L Sarmiento ${ }^{2}$, lan Forde ${ }^{3}$ and Tatiana Velasco ${ }^{1}$ \\ ${ }^{1}$ School of Government, Universidad de los Andes, Carrera 1 No. 19-27 (Au, 217), Bogotá, Colombia: \\ ${ }^{2}$ Department of Public Health, School of Medicine, Universidad de los Andes, Bogotá, Colombia: \\ ${ }^{3}$ Department of Epidemiology and Public Health, University College London, London, UK
}

Submitted 28 September 2011: Final revision received 6 July 2012: Accepted 26 July 2012: First published online 13 September 2012

\begin{abstract}
Objective: To examine socio-economic inequalities in malnutrition among Colombian children and adolescents, and to assess the contribution of individual-, household- and community-level factors to those inequalities.

Design: Cross-sectional data were used from two sources: 2005 Colombian Demographic and Health Survey and 2005 Colombian census. Malnutrition outcomes included stunting and overweight. Multilevel Poisson models were used to estimate the association between individual, household and contextual characteristics and malnutrition. Changes in prevalence ratios of the poorest quintile ( $v$. richest) were compared to assess the contribution of different characteristics to inequalities in malnutrition.

Setting: Population-based, representative of Colombia.

Subjects: Children and adolescents $<18$ years of age ( $n$ 30779) from the Colombian Demographic and Health Survey.

Results: Children and adolescents living in the poorest households were close to five times more likely to be stunted, while those from the richest households were $1 \cdot 3-2 \cdot 8$ times more likely than their poorest counterparts to be overweight. Care practices and household characteristics, particularly mother's education, explained over one-third of socio-economic inequalities in stunting. The proportion explained by access to services was not negligible (between $6 \%$ and $14 \%)$. Access to sanitation was significantly associated with a lower prevalence of stunting for all age groups. Between $14 \%$ and $32 \%$ of socio-economic disparities in overweight were explained by maternal and household characteristics. Mother's overweight was positively associated with overweight of the child. Conclusion: Socio-economic inequalities in stunting and overweight coexist among children and adolescents in Colombia. Malnutrition inequalities are largely explained by household characteristics, suggesting the need for targeted interventions.
\end{abstract}

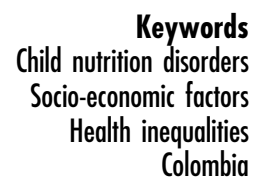

The various manifestations of child malnutrition have been consistently demonstrated to exhibit stark social patterning in diverse settings ${ }^{(1-4)}$. Typically, in low- and middle-income countries, undernutrition is more common in low-income groups and the phenomenon of child overweight is more prevalent to wealthier households ${ }^{(5)}$. Although differential access to food may explain such wealth-based patterning, other factors may be relevant such as parenting skill, family composition or contextual factors, such as access to sanitation and rurality ${ }^{(6-9)}$. Identifying these drivers is important to inform effective health policy. The issue is particularly pressing since relatively little is known about the drivers of socio-economic inequalities in child malnutrition, in contrast to the situation in adults where determinants of social inequalities in nutritional status are better described ${ }^{(10)}$.

Adding to the urgency of the task is the phenomenon of the nutrition transition. This refers to the shifting burden of obesity from socio-economically privileged groups to the poor, which has been observed over recent decades in several low- and middle-income countries ${ }^{(11,12)}$. In some settings, under- and overnourished individuals exist even in the same household ${ }^{(13,14)}$. If the poorest groups in society are to avoid a simultaneous burden of under- and overnutrition, it is essential to advance our understanding of the biological, psychological and socioeconomic drivers of childhood malnutrition and the reasons why they increasingly affect poorer households. 
The present paper seeks to add to the field by quantifying the contribution of individual-, household- and community-level characteristics to the socio-economic inequalities of malnutrition observed in Colombian children aged 0-17 years. We focus on children and adolescents because nutritional morbidities manifest at this life stage have lifelong physical and socio-economic consequences $^{(15-20)}$. Furthermore, limited evidence is available about the determinants of socio-economic inequalities in nutritional status among this age group. Colombia is a unique setting in which to explore the issue for several reasons. First, both under- and overnutrition are prevalent (national survey data in 2010 reported that 15.9\% of Colombian children $<5$ years of age had a height-for-age $Z$-score $<-2$ and $4.8 \%$ a weight-for-height $Z$-score $>2$, using 2006 WHO curves $\left.{ }^{(21)}\right)$. Second, detailed national household survey data are available and income inequality is stark: the Gini coefficient, a measure of income inequality in which 0 indicates perfect equality and 1 maximal inequality, was 0.587 in 2009 , the highest in South America $^{(22)}$. Finally, the nutrition transition appears very much in evidence in Colombia. Comparison of national survey data from 2005 and 2010 suggests that the obesity gradient has already tipped against women in the poorest households ${ }^{(21,23,24)}$ : among women aged 15-49 years in the lowest national wealth quintile, prevalence increased from $10 \cdot 8 \%$ to $15 \cdot 0 \%$ between 2005 and 2010 , compared with a marginal increase from $12 \cdot 0 \%$ to $12 \cdot 6 \%$ among women in the highest quintile ${ }^{(21,23)}$.

\section{Methods}

\section{Conceptual framework}

To the best of our knowledge, a conceptual framework which attempts to map the drivers of simultaneous under- and overnutrition at the community level does not exist. Accordingly, we draw upon separate frameworks to guide our analysis. For undernutrition, we use that proposed by Mosley and Chen ${ }^{(25)}$ and for obesity, that proposed by Davison and Birch ${ }^{(26)}$. Both frameworks understand malnutrition to result from the interplay between proximate, household and community-level factors. Proximate factors include the biological status of mother and child such as parity and specific child-care behaviours such as feeding practices. Household factors include income, household composition and educational attainment, which may be relevant to achieving food security. Community-level factors include access to clean water, sanitation and medical services ${ }^{(1)}$. Altered nutrient absorption secondary to chronic intestinal infection in poorly sanitized environments is an increasingly recognized cause of poor growth in children ${ }^{(27)}$. Similarly, the link between urban settings and childhood obesity is well established, mediated through the adoption of Western diets and decreased opportunities for recreational play ${ }^{(28)}$.
We set out the conceptual framework used in Fig. 1, recognizing the multiple drivers of childhood nutritional status and the complex interplay between them. Our framework embodies the intuitive ordering of determinants proposed by Davison and Birch, sorting them into three natural categories at individual, household and community levels. Our framework also allows determinants to influence each other in a reciprocal manner, as might household wealth and number, age and sex of children, for example. We seek to quantify the extent to which drivers at individual, household and community levels, particularly those which are modifiable, account for socio-economic inequalities in abnormal nutritional status of Colombian children. In so doing, we aim to identify the areas where policy may be most effectively directed to reduce inequality.

\section{Sampling design and study population}

Our analysis used cross-sectional data from the 2005 Colombian Demographic and Health Survey (Encuesta Nacional de Demografía y Salud, ENDS), part of the Colombian Demographic and Health Survey (DHS). The survey applied a multistage, stratified, population-based cluster sampling design. The sample for the current analysis comprised 30779 children $<18$ years of age living with their mothers. Additionally, we obtained 2005 census sector identifiers for every household in the sample. Census sectors are areas containing between 120 and 200 households, comparable to census tracts in the USA. Individual data were merged with census sector data to model socioeconomic indicators at the community level.

The questionnaire contained both household and individual components and was administered in the home by female interviewers equipped with computerassisted personal interview technology. Local ethical approval was granted by the Profamilia Institutional Review Board on Research Involving Human Subjects.

\section{Measures}

\section{Outcome measurement: stunting and overweight}

We measured malnutrition using two dependent variables: (i) stunting (or chronic undernutrition), defined as heightfor-age $Z$-score at least two standard deviations below the median according to the 2006 WHO child growth standards for children aged $<5$ years ${ }^{(29)}$ and the 2007 WHO reference for children aged $5-17$ years $^{(30)}$; and (ii) overweight, defined as age- and sex-specific BMI $Z$-score greater than two standard deviations above the median according to the 2006 WHO child growth standards for children aged $<5$ years $^{(29)}$ and the 2007 WHO reference for children aged 5-17 years $^{(30)}$.

Children's weight and height were measured in households by trained personnel using calibrated equipment. Specifically, weight was measured with digital scales (SECA model 770) adjusted for Colombia's latitude, 


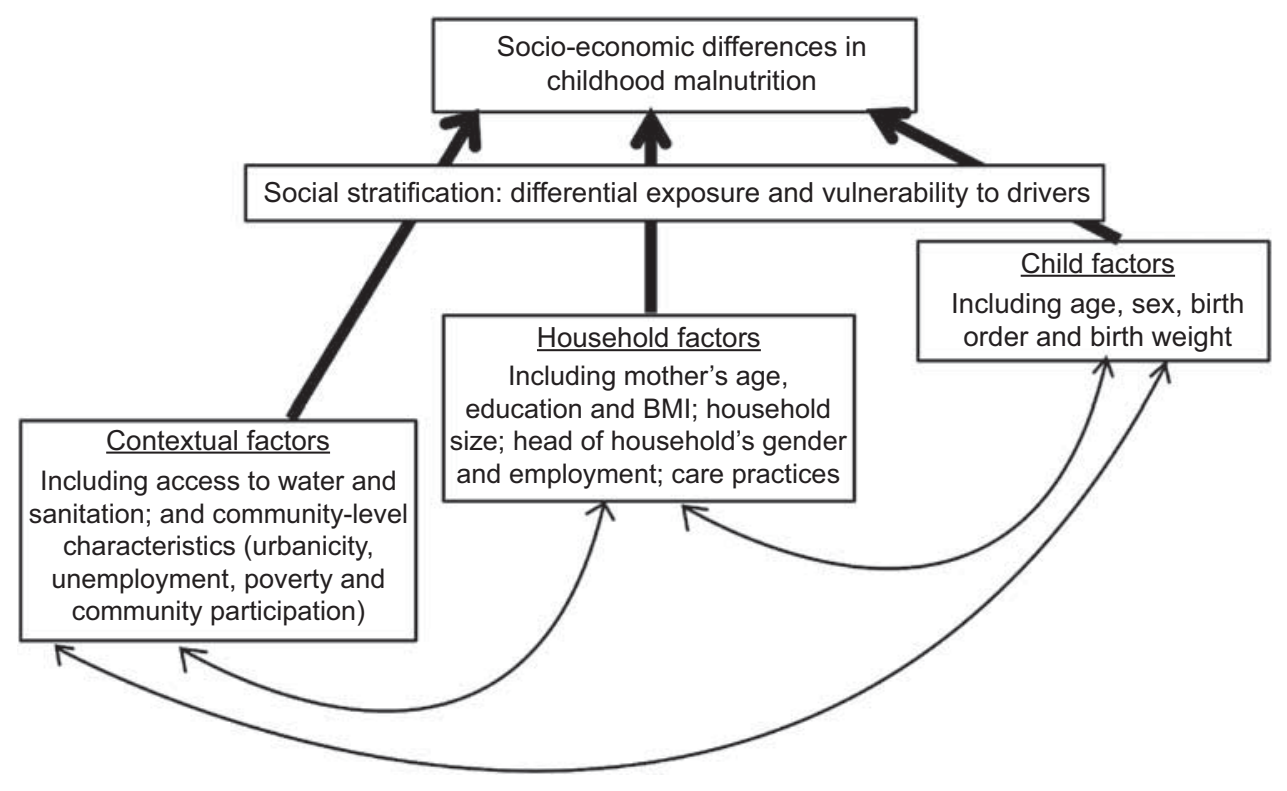

Fig. 1 Conceptual framework of potential determinants for child nutritional status

while height was measured with a portable stadiometer (Shorr Productions).

\section{Independent variables}

Household socio-economic status. We used the World Bank's wealth index (WI) ${ }^{(31)}$ to stratify households by wealth quintiles. WI is a measure of economic status constructed to allow analysis of health equity using DHS data $^{(32,33)}$. Since DHS does not collect data on income or expenditures, WI uses principal components analysis to take into account a set of assets such as radio, television, refrigerator, car or motorcycle; and household dwelling characteristics such as source of drinking water, quality of flooring or installation of a toilet. WI is a proxy for long-term economic circumstances and allows division of the population into socio-economic groups and identification of the poorest (bottom quintile) and the wealthiest (top quintile) households. While other definitions of socio-economic status exist, such as those based upon occupation or education, the WI is our preferred indicator in the present paper because it captures a rich array of household-level socio-economic and quality-of-life markers and is well validated, widely used and highly correlated with other uni-dimensional indicators such as occupation $^{(34-36)}$.

Individual and bousebold characteristics. Children's individual characteristics included age, sex and birth order. For children $<5$ years of age, we also included birth weight. Household characteristics included mother's age, mother's BMI, mother's educational attainment (no education, elementary school, secondary school or higher education), number of children in the household, household size, family structure (complete nuclear family, incomplete nuclear family, complete extended family or incomplete extended family), female head of household, whether or not the household head is employed and whether or not the child has health insurance. For children $<5$ years of age we also included care practices such as breast-feeding for at least 1 month and immunization (whether or not the child has had the required doses of diphtheria-pertussis-tetanus vaccine for his/her age).

Contextual factors. Contextual factors included access to potable water and sanitation and community-level characteristics related to area of residence (urban $v$. rural), educational attainment (proportion of women and men who had completed high school), community participation (proportion of households that were participating in a community organization), poverty (proportion of households that were poor based on the Index of Unsatisfied Basic Needs, which classifies household as poor if at least one of the following applies: inadequate housing, overcrowding, few adults employed relative to the number of people in the household, children not attending school), employment (proportion of women and men 15-64 years old who were employed) and proportion of female heads of household at the census-sector level.

\section{Statistical analysis}

We conducted the analysis separately for pre-school children $(<5$ years of age) and children and adolescents aged 5-17 years because there were specific variables related to health and health-care practices that were measured only among pre-schoolers. Furthermore, preschool children in Colombia receive targeted national nutrition and welfare programmes.

Initially, we estimated weighted prevalences of stunting and overweight by wealth quintile stratified by age group and estimated differences between wealth quintiles. 
Next, given the clustering of children within households and households within census sectors, and to allow the estimation of prevalence ratios, we conducted multilevel Poisson models using the statistical software package STATA version 11 (program 'gllamm'). For each dichotomous outcome (stunting $v$. non-stunting or overweight $v$. nonoverweight), we estimated three-level models. Level 1 models account for individual children; level 2 for children nested into households; and level 3 for households nested into census sectors. All models assumed a random intercept. In the first (unadjusted) model, we included a dummy variable for each of the wealth quintiles, with the richest group being the referent category.

Then, to explore the contribution of individual-, household- and community-level characteristics to inequalities in child malnutrition, we aggregated the following vectors of variables into the model sequentially (models 2, 3 and 4): child's health and demographic characteristics; mother's and household's characteristics (and care practices for children $<5$ years of age); and contextual characteristics which include access to services and community-level characteristics. To determine each vector's contribution in explaining malnutrition inequalities, we compared the relative change in prevalence ratios on the poorest WI quintile indicator (relative to the richest quintile) between models (as we added each vector or characteristic), according to the following expression:

$$
\frac{W_{i}-W_{i-1}}{W_{i}} \times 100
$$

where $W_{i}$ is the estimated prevalence ratio (PR) on the poorest WI quintile indicator (relative to the richest quintile) from model $i$ and $W_{i-1}$ is the PR estimate from the model $i-1$.

\section{Results}

Descriptive statistics by age group for the full sample (see Table 1) indicated that children $<5$ years of age had younger and better educated mothers than children and adolescents aged 5-17 years, had fewer siblings and were more likely to live in a complete extended family. The double burden of malnutrition was observable for both age groups. Thirteen per cent of children and adolescents were stunted (in both age groups); while $25 \%$ of those $<5$ years of age and $14 \%$ of those aged 5-17 years were overweight.

\section{Socio-economic inequalities in childbood malnutrition}

Socio-economic inequalities in malnutrition were observable for both age groups, although they operated differently depending on outcome. In the poorest quintile, the prevalence of stunting was $21 \cdot 8 \%$ among children $<5$ years of age and $25 \cdot 9 \%$ among children and adolescents aged 5-17 years. In contrast, in the richest quintile, $4 \cdot 5 \%$ of children $<5$ years of age and $5 \cdot 6 \%$ of children and adolescents aged 5-17 years were stunted (Fig. 2a). The prevalence of overweight for children $<5$ years of age was $23.7 \%$ and $29.0 \%$ in the poorest and richest quintiles, respectively. Among children and adolescents aged 5-17 years, differences in overweight were more marked: $7 \cdot 5 \%$ in the poorest quintile and $21.5 \%$ in the richest quintile (Fig. 2b).

Children in the poorest quintile were about five times more likely than children in the richest quintile to be stunted (unadjusted $\mathrm{PR}=5 \cdot 11,95 \%$ CI $3 \cdot 45,7 \cdot 58$ for children $<5$ years of age; unadjusted $\mathrm{PR}=4 \cdot 72,95 \% \mathrm{CI}$ 3.94, 5.65 for children and adolescents aged 5-17 years; Tables 2 and 3). Among children $<5$ years old, estimated inequalities in stunting were larger for girls than for boys, although the difference was not statistically significant $(\mathrm{PR}=4 \cdot 20,95 \%$ CI $2 \cdot 63,6 \cdot 71$ for boys and $\mathrm{PR}=7 \cdot 58$, $95 \%$ CI $3 \cdot 70,15 \cdot 54$ for girls).

Socio-economic differences for overweight were also significant, but against children in the richest quintile. The largest difference was observable for children and adolescents aged 5-17 years, with those belonging to the richest quintile being close to three times more likely to be overweight than those in the poorest quintile (unadjusted PR $=2 \cdot 77,95 \%$ CI 2•43, 3·16; Tables 4 and 5). Among children and adolescents aged $5-17$ years, inequalities were larger for boys than for girls ( $\mathrm{PR}=3 \cdot 72,95 \% \mathrm{CI} 3 \cdot 08,4 \cdot 50$ for boys and PR $=2 \cdot 07,95 \%$ CI $1 \cdot 75,2 \cdot 46$ for girls).

\section{Determinants of socio-economic inequalities in childbood stunting}

Over one-third (36\%) of the disparity in stunting between the poorest and richest quintile for children $<5$ years of age was explained by mother's education and care practices (Model 3, Table 2). Contextual characteristics did not further account for the socio-economic inequality in stunting (Model 4). However, when we added access to services alone (without community-level characteristics) to Model 3, access to water and sanitation explained an additional $14 \%$ of the difference in stunting between children in the poorest and the riches quintiles.

For school-aged children and adolescents, $44 \%$ of the inequality in stunting was explained by mother's education, mother's BMI and household characteristics. In contrast to the findings for children $<5$ years old, access to basic public utilities explained very little (an additional 6\%) of the WI difference observed for children and adolescents aged 5-17 years once household characteristics and mother's education were controlled for. Community-level characteristics did not further explain inequalities for stunting (Table 3).

The multivariate results revealed a strong association between stunting and mother's education for both age groups. As expected, children whose mothers had low educational attainment were more likely to be stunted. Also, access to sanitation was significantly associated with 
Table 1 Descriptive statistics on individual, household and contextual characteristics of Colombian children and adolescents, 2005 Colombian Demographic and Health Survey

\begin{tabular}{|c|c|c|c|c|c|}
\hline & \multicolumn{2}{|c|}{$\begin{array}{l}\text { Children }<5 \text { years } \\
\text { of age }\left(n 6963^{*}\right)\end{array}$} & \multicolumn{2}{|c|}{$\begin{array}{l}\text { Children and adolescents } \\
\text { aged } 5-17 \text { years }\left(n 23816^{\star}\right)\end{array}$} & \multirow[b]{2}{*}{$P$ valuet } \\
\hline & Weighted mean or $\%$ & $95 \% \mathrm{Cl}$ & Weighted mean or $\%$ & $95 \% \mathrm{Cl}$ & \\
\hline Wealth index (\%) & & & & & $<0.001$ \\
\hline 1st quintile & $14 \cdot 3$ & $13 \cdot 5,15 \cdot 1$ & $17 \cdot 8$ & $17 \cdot 3,18 \cdot 3$ & \\
\hline 2nd quintile & $25 \cdot 3$ & $24 \cdot 3,26 \cdot 3$ & $22 \cdot 0$ & $24 \cdot 5,22 \cdot 5$ & \\
\hline 3rd quintile & $26 \cdot 0$ & $25 \cdot 0,27 \cdot 0$ & $22 \cdot 9$ & $21 \cdot 7,22 \cdot 8$ & \\
\hline 4th quintile & $21 \cdot 0$ & $20 \cdot 0,21 \cdot 9$ & $20 \cdot 9$ & $20 \cdot 3,21 \cdot 4$ & \\
\hline 5th quintile & $13 \cdot 5$ & $12 \cdot 7,14 \cdot 3$ & $17 \cdot 0$ & $16 \cdot 5,17 \cdot 5$ & \\
\hline \multicolumn{6}{|l|}{ Children's health and demographic characteristics } \\
\hline Age (years) & $1 \cdot 9$ & $1 \cdot 9,2 \cdot 0$ & $10 \cdot 4$ & $10 \cdot 4,10 \cdot 4$ & $<0.001$ \\
\hline Male $(\%)$ & $50 \cdot 3$ & $49 \cdot 1,51 \cdot 5$ & $48 \cdot 9$ & $48 \cdot 3,49 \cdot 6$ & 0.208 \\
\hline Birth order & $2 \cdot 2$ & $2 \cdot 2,2 \cdot 2$ & $2 \cdot 4$ & $2 \cdot 4,2 \cdot 4$ & $<0.001$ \\
\hline Birth weight $(\mathrm{kg})$ & $3 \cdot 2$ & $3 \cdot 2,3 \cdot 2$ & & & \\
\hline \multicolumn{6}{|l|}{ Household characteristics } \\
\hline Mother's age (years) & $27 \cdot 5$ & $27 \cdot 4,27 \cdot 7$ & $35 \cdot 9$ & $35 \cdot 8,36 \cdot 0$ & $<0.001$ \\
\hline Mother's BMI $\left(\mathrm{kg} / \mathrm{m}^{2}\right)$ & $24 \cdot 5$ & $24 \cdot 4,24 \cdot 6$ & $25 \cdot 9$ & $25 \cdot 9,26 \cdot 0$ & $<0.001$ \\
\hline Mother's education (\%) & & & & & $<0.001$ \\
\hline No education & $1 \cdot 6$ & $1 \cdot 3,1 \cdot 8$ & $4 \cdot 2$ & $3 \cdot 9,4 \cdot 5$ & \\
\hline Elementary school & $27 \cdot 1$ & $26 \cdot 0,28 \cdot 1$ & $39 \cdot 3$ & $38 \cdot 6,39 \cdot 9$ & \\
\hline Secondary school & $57 \cdot 6$ & $56 \cdot 5,58 \cdot 8$ & $45 \cdot 3$ & $44 \cdot 7,45 \cdot 9$ & \\
\hline Higher education & $13 \cdot 8$ & $12 \cdot 9,14 \cdot 6$ & $11 \cdot 2$ & $10 \cdot 8,11 \cdot 6$ & \\
\hline Number of children & $2 \cdot 3$ & $2 \cdot 3,2 \cdot 4$ & $3 \cdot 3$ & $3 \cdot 3,3 \cdot 4$ & $<0.001$ \\
\hline Household size (no. of people) & $5 \cdot 6$ & $5 \cdot 5,5 \cdot 7$ & $5 \cdot 8$ & $5 \cdot 8,5 \cdot 8$ & $<0.001$ \\
\hline Family structure (\%) & & & & & $<0.001$ \\
\hline Complete nuclear family & $45 \cdot 4$ & $44 \cdot 2,46 \cdot 5$ & $50 \cdot 4$ & $49 \cdot 8,51 \cdot 1$ & \\
\hline Incomplete nuclear family & $5 \cdot 3$ & $4 \cdot 7,5 \cdot 8$ & $9 \cdot 9$ & $9 \cdot 5,10 \cdot 3$ & \\
\hline Complete extended family & $27 \cdot 3$ & $26 \cdot 3,28 \cdot 4$ & $21 \cdot 4$ & $20 \cdot 9,22 \cdot 0$ & \\
\hline Incomplete extended family & $22 \cdot 1$ & $21 \cdot 1,23 \cdot 0$ & $18 \cdot 3$ & $17 \cdot 8,18 \cdot 8$ & \\
\hline Female head of household (\%) & $23 \cdot 8$ & $22 \cdot 8,24 \cdot 8$ & $25 \cdot 6$ & $25 \cdot 0,26 \cdot 1$ & $<0.001$ \\
\hline Head of household employed (\%) & $80 \cdot 4$ & $79 \cdot 4,81 \cdot 3$ & $80 \cdot 7$ & $80 \cdot 2,81 \cdot 2$ & 0.127 \\
\hline Health insurance (insured, \%) & $67 \cdot 8$ & $66 \cdot 7,68 \cdot 9$ & $69 \cdot 5$ & $68 \cdot 9,70 \cdot 0$ & 0.001 \\
\hline \multicolumn{6}{|l|}{ Care practices } \\
\hline Breast-fed (yes, \%) & $98 \cdot 0$ & $97 \cdot 7,98 \cdot 4$ & - & - & \\
\hline DPT immunization complete for age (\%) & $89 \cdot 4$ & $88 \cdot 7,90 \cdot 1$ & - & - & \\
\hline \multicolumn{6}{|l|}{ Contextual characteristics } \\
\hline Access to water (yes, \%) & $91 \cdot 6$ & $90 \cdot 9,92 \cdot 2$ & $89 \cdot 9$ & $89 \cdot 5,90 \cdot 3$ & 0.001 \\
\hline Access to sanitation (yes, \%) & $90 \cdot 0$ & $89 \cdot 2,90 \cdot 7$ & $87 \cdot 1$ & $86 \cdot 7,87 \cdot 6$ & $<0.001$ \\
\hline \multicolumn{6}{|l|}{ Community-level characteristicsł } \\
\hline $\begin{array}{l}\text { Women } \geq 18 \text { years old with high school } \\
\text { completed (\%) }\end{array}$ & $33 \cdot 4$ & $32 \cdot 8,33 \cdot 9$ & $32 \cdot 9$ & $32 \cdot 6,33 \cdot 2$ & $0 \cdot 184$ \\
\hline Men $\geq 18$ years old with high school completed (\%) & $32 \cdot 2$ & $31 \cdot 6,32 \cdot 8$ & $32 \cdot 1$ & $31 \cdot 7,32 \cdot 4$ & 0.654 \\
\hline Community participation (\%) & $23 \cdot 7$ & $21 \cdot 0,26 \cdot 5$ & $19 \cdot 5$ & $18 \cdot 4,20 \cdot 1$ & 0.001 \\
\hline Poverty according to IUBN (\%) & $25 \cdot 5$ & $24 \cdot 9,26 \cdot 0$ & $26 \cdot 9$ & $26 \cdot 6,27 \cdot 2$ & $<0.001$ \\
\hline Women's employment $15-64$ years old (\%) & $31 \cdot 2$ & $30 \cdot 7,31 \cdot 7$ & $30 \cdot 0$ & $29 \cdot 8,30 \cdot 3$ & $<0.001$ \\
\hline Men's employment $15-64$ years old (\%) & $69 \cdot 8$ & $69 \cdot 4,70 \cdot 2$ & $69 \cdot 3$ & $69 \cdot 0,69 \cdot 5$ & 0.016 \\
\hline Female head of household (\%) & $27 \cdot 2$ & $26 \cdot 8,27 \cdot 6$ & $26 \cdot 5$ & $26 \cdot 3,26 \cdot 7$ & 0.002 \\
\hline \multicolumn{6}{|l|}{ Malnutrition } \\
\hline Stunted $(\%) \S$ & $13 \cdot 3$ & $12 \cdot 5,14 \cdot 1$ & $13 \cdot 5$ & $13 \cdot 1,14 \cdot 0$ & 0.726 \\
\hline Overweight (\%)\| & $25 \cdot 1$ & $24 \cdot 1,26 \cdot 2$ & $14 \cdot 2$ & $133 \cdot 8,14 \cdot 7$ & $<0.001$ \\
\hline
\end{tabular}

DPT, diphtheria-pertussis-tetanus; IUBN, Index of Unsatisfied Basic Needs.

*Unweighted sample size.

tComparison between children $<5$ years of age and children and adolescents aged 5-17 years (Pearson's $\chi^{2}$ test for categorical variables; $t$ test of difference between means for continuous variables).

$\ddagger$ At the census-sector level.

\$Height-for-age $Z$-score $<-2$ (according to 2006 WHO child growth standards for children aged $<5$ years ${ }^{(29)}$ and 2007 WHO reference for children aged $5-17$ years $\left.^{(30)}\right)$.

$\|$ Age- and sex-specific BMI $Z$-score $>2$ (according to 2006 WHO child growth standards for children aged $<5$ years ${ }^{(29)}$ and 2007 WHO reference for children aged 5-17 years ${ }^{(30)}$ ).

a lower prevalence of stunting ( $\mathrm{PR}=0 \cdot 69,95 \%$ CI 0.56, 0.84 for children $<5$ years of age and $\mathrm{PR}=0.84,95 \% \mathrm{CI}$ $0 \cdot 75,0.93$ for children and adolescents aged 5-17 years). For both age groups, a strong association between poverty and stunting remained after controlling for place of residence, suggesting that living in an urban area is not necessarily a protective factor against undernutrition.

\section{Determinants of socio-economic inequalities in childbood overweight}

Only $14 \%$ of the socio-economic disparity in overweight for children $<5$ years of age (Table 4 ) and close to onethird $(32 \%)$ of the disparity in overweight among children and adolescents aged 5-17 years were explained by maternal and household characteristics (Table 5). Children 

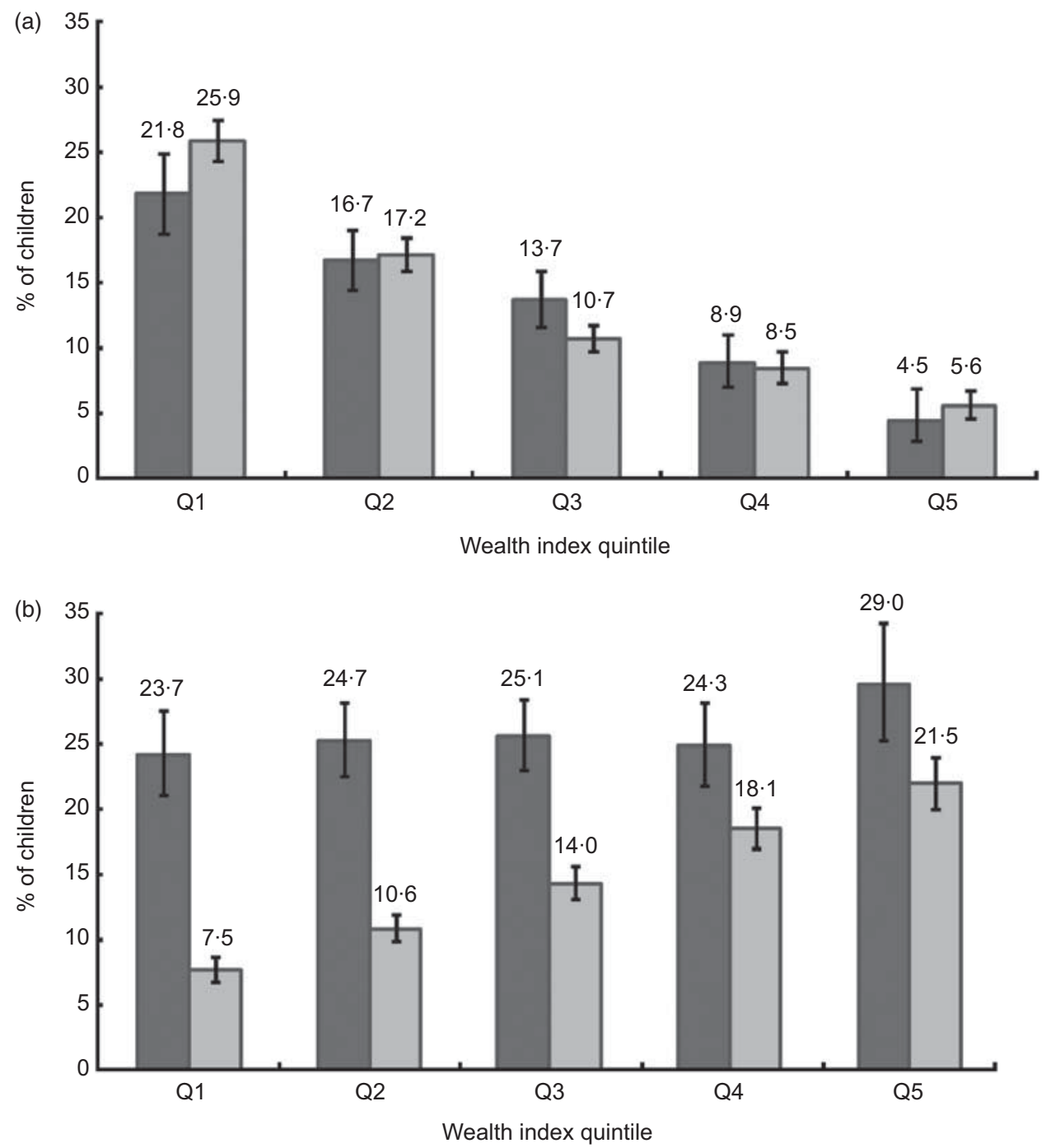

Fig. 2 Percentage of (a) stunting and (b) overweight by quintile of wealth index (Q1, poorest; Q5; richest) and age group ( $\square$, children $<5$ years of age; $\square$, children and adolescents aged 5-17 years), 2005 Colombian Demographic and Health Survey. Stunting $=$ height-for-age $Z$-score $<-2$ and overweight $=$ age- and sex-specific BMI Z-score $>2$ (according to 2006 WHO child growth standards for children aged $<5$ years $^{(29)}$ and 2007 WHO reference for children aged 5-17 years $\left.{ }^{(30)}\right)$

with mothers who were overweight or obese were significantly more likely to be overweight $(\mathrm{PR}=1 \cdot 43$, $95 \%$ CI $1.29,1.58$ for children $<5$ years old and $\mathrm{PR}=2 \cdot 17,95 \%$ CI $2 \cdot 00,2 \cdot 34$ for children and adolescents aged $5-17$ years). Although community-level characteristics did not provide further explanation of socio-economic differences in overweight, it is important to note that the percentage of female heads of household at census-sector level was positively associated with overweight for children $<5$ years of age. Also, once individual and household characteristics were controlled for, there was a negative marginal association between community participation and overweight in children and adolescents aged 5-17 years $(\mathrm{PR}=0.92,95 \% \mathrm{CI} 0 \cdot 85,1 \cdot 01)$, suggesting that this contextual variable could be a protective factor for overweight or among this age group (Table 5).

\section{Discussion}

\section{Main result}

Analysis of 2005 national survey data in Colombian children and adolescents aged 0-17 years shows that marked social inequalities coexist in the prevalence of undernutrition (against poorer children) and overnutrition (against more privileged children). Children in the poorest households experience significant rates of under- and overnutrition. Household factors and access to services account for a greater proportion of the differences observed than community-level characteristics. In particular, mother's education and household sanitation in the case of stunting and mother's BMI in the case of overweight account for a substantial portion of observed inequalities. 
Table 2 Hierarchical three-level Poisson regression models predicting stunting of children $<5$ years of age, 2005 Colombian Demographic and Health Survey 


\begin{tabular}{|c|c|c|c|c|c|c|c|c|}
\hline & \multicolumn{2}{|c|}{ Model 1} & \multicolumn{2}{|c|}{ Model 2} & \multicolumn{2}{|c|}{ Model 3} & \multicolumn{2}{|c|}{ Model 4} \\
\hline & PR & $95 \% \mathrm{Cl}$ & PR & $95 \% \mathrm{Cl}$ & PR & $95 \% \mathrm{Cl}$ & PR & $95 \% \mathrm{Cl}$ \\
\hline \multicolumn{9}{|l|}{ Immunization complete } \\
\hline No & & & & & Ref. & - & Ref. & - \\
\hline Yes & & & & & $0 \cdot 89$ & $0 \cdot 73,1 \cdot 08$ & $0 \cdot 90$ & $0.74,1.09$ \\
\hline \multicolumn{9}{|l|}{ Contextual characteristics } \\
\hline \multicolumn{9}{|l|}{ Access to water } \\
\hline No & & & & & & & Ref. & - \\
\hline Yes & & & & & & & $1 \cdot 15$ & $0.93,1.41$ \\
\hline \multicolumn{9}{|l|}{ Access to sanitation } \\
\hline No & & & & & & & Ref. & \\
\hline Yes & & & & & & & 0.69 & $0.56,0.84$ \\
\hline \multicolumn{9}{|l|}{ Urban } \\
\hline No & & & & & & & Ref. & - \\
\hline Yes & & & & & & & $1 \cdot 08$ & $0 \cdot 88,1 \cdot 33$ \\
\hline \multicolumn{9}{|l|}{ Community-level characteristics* } \\
\hline Women with high school completed (\%) & & & & & & & $1 \cdot 00$ & $1 \cdot 00,1.01$ \\
\hline Men with high school completed (\%) & & & & & & & $1 \cdot 00$ & $0.99,1.00$ \\
\hline Community participation (\%) & & & & & & & 1.01 & $0.92,1.09$ \\
\hline Poverty (\%) & & & & & & & $1 \cdot 00$ & $0.99,1.00$ \\
\hline Women's employment $15-64$ years old (\%) & & & & & & & $1 \cdot 00$ & $0.99,1.00$ \\
\hline Men's employment $15-64$ years old (\%) & & & & & & & $1 \cdot 00$ & $1.00,1.01$ \\
\hline Female head of household (\%) & & & & & & & $1 \cdot 01$ & $1 \cdot 00,1 \cdot 01$ \\
\hline Variance and covariance within household & 0.00 & 0.00 & 0.00 & 0.00 & 0.00 & 0.00 & 0.00 & 0.00 \\
\hline Variance and covariance within census sectors & 0.09 & 0.04 & 0.06 & 0.04 & 0.05 & 0.03 & $0 \cdot 03$ & 0.03 \\
\hline No. of households & 5942 & & & & & & & \\
\hline No. of census sectors & 1125 & & & & & & & \\
\hline$n$ & 6963 & & & & & & & \\
\hline
\end{tabular}

PR, prevalence ratio; Ref., referent category.

All estimates are conditional on random effects.

${ }^{*}$ At the census-sector level. 
Table 3 Hierarchical three-level Poisson regression models predicting stunting of children and adolescents aged 5-17 years, 2005 Colombian Demographic and Health Survey

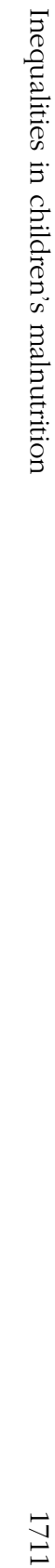




\section{Generalizability and comparison with otber studies}

Colombia occupies a mid-table position regarding Human Development Index (79th in 2010) and per capita Gross Domestic Product (\$US 8959, 2010 estimate). Hence, despite the socio-political context of each country being unique, our findings are likely to be pertinent to several countries at a similar stage of development and with a double burden of stunting and overweight at the community level.

The positive association between economic status and overweight is consistent with other studies from preschoolers in developing countries ${ }^{(5)}$ and from adult populations in middle-income countries ${ }^{(10,11)}$. The negative association between economic status and stunting is also consistent with previous findings for children $<5$ years of age in Asia, Latin America and Africa ${ }^{(1,2,37)}$ and among pregnant women in Colombia ${ }^{(24)}$. In agreement with Menon et al. ${ }^{(2)}$ we found that inequalities in malnutrition were significant both in urban and rural areas. Likewise, McDonald et al. reported similar rates of stunting and overweight in children aged 5-12 years in Bogotá, as well as a positive association with socioeconomic status and maternal BMI in the case of overweight ${ }^{(38)}$. Although their study benefits from data on dietary patterns, community-level characteristics were not included and household characteristics were limited to maternal education, household asset ownership and socio-economic stratum.

The association between household characteristics and care practices and malnutrition inequalities is consistent with previous research. In the case of stunting, Ruel et $a l .{ }^{(39)}$ found that most of the difference in chronic stunting between low- and high-income pre-schoolers was associated with differences in caring practices. Likewise, Smith et al. ${ }^{(7)}$ demonstrated that access to sanitation was strongly associated with nutritional status both in urban and rural settings.

The association between maternal education and stunting should be interpreted with caution. Children of low educated mothers may be stunted more often because poorly educated mothers have worse health behaviours, worse care practices or worse living conditions than more educated mothers. Each reason is potentially modifiable by appropriate policy. Alternatively, such children's stunting may reflect limited intra-uterine growth, and thus be determined by their mother's environment during her pregnancy, her childhood or even her own intra-uterine phase ${ }^{(40)}$. Such intergenerational transmission of height is not amenable to policy intervention - at least not in the short term.

\section{Strengths and weaknesses}

To our knowledge, the present study is the first one to examine the extent to which factors at the individual, household and community levels account for malnutrition 
Table 4 Hierarchical three-level Poisson regression models predicting overweight of children $<5$ years of age, 2005 Colombian Demographic and Health Survey

\begin{tabular}{|c|c|c|c|c|c|c|c|c|}
\hline & \multicolumn{2}{|c|}{ Model 1} & \multicolumn{2}{|c|}{ Model 2} & \multicolumn{2}{|c|}{ Model 3} & \multicolumn{2}{|c|}{ Model 4} \\
\hline & PR & $95 \% \mathrm{Cl}$ & $\mathrm{PR}$ & $95 \% \mathrm{Cl}$ & PR & $95 \% \mathrm{Cl}$ & PR & $95 \% \mathrm{Cl}$ \\
\hline \multicolumn{9}{|l|}{ Wealth index } \\
\hline 1st quintile & Ref. & - & Ref. & - & Ref. & - & Ref. & - \\
\hline 2nd quintile & 1.07 & $0.93,0.25$ & 1.05 & $0.91,1.22$ & 1.02 & $0 \cdot 87,1 \cdot 19$ & $1 \cdot 11$ & $0.92,1.34$ \\
\hline 3rd quintile & $1 \cdot 11$ & $0.96,1.30$ & 1.09 & $0.94,1.28$ & 1.02 & $0 \cdot 87,1 \cdot 19$ & $1 \cdot 12$ & $0.91,1.38$ \\
\hline 4th quintile & $1 \cdot 13$ & $0.96,1.33$ & $1 \cdot 10$ & $0.93,1.30$ & 0.99 & $0 \cdot 83,1 \cdot 18$ & $1 \cdot 10$ & $0 \cdot 87,1 \cdot 38$ \\
\hline 5th quintile & 1.33 & $1 \cdot 11,1 \cdot 60$ & $1 \cdot 30$ & $1 \cdot 08,1.57$ & $1 \cdot 12$ & $0.91,1.38$ & $1 \cdot 23$ & $0.95,1.58$ \\
\hline \multicolumn{9}{|c|}{ Child health and demographic characteristics } \\
\hline Age & & & 0.94 & $0.91,0.97$ & 0.93 & $0.89,0.96$ & 0.93 & $0.89,0.96$ \\
\hline Male & & & 1.04 & $0 \cdot 94,1 \cdot 14$ & 1.04 & $0.94,1 \cdot 14$ & 1.03 & $0.94,1 \cdot 14$ \\
\hline Birth order & & & 0.97 & $0.94,1.00$ & 0.94 & $0.84,1.06$ & 0.94 & $0.84,1.06$ \\
\hline \multicolumn{9}{|l|}{ Birth weight } \\
\hline Normal: $2 \cdot 5-3 \cdot 0 \mathrm{~kg}$ & & & Ref. & - & Ref. & - & Ref. & - \\
\hline$<2.5 \mathrm{~kg}$ (low birth weight) & & & 0.82 & $0.63,1.07$ & $0 \cdot 82$ & $0.63,1.06$ & 0.82 & $0.63,1.06$ \\
\hline $3 \cdot 0-3.5 \mathrm{~kg}$ & & & $1 \cdot 26$ & $1 \cdot 08,1 \cdot 46$ & $1 \cdot 24$ & $1 \cdot 07,1 \cdot 44$ & $1 \cdot 24$ & $1 \cdot 07,1 \cdot 44$ \\
\hline$>3.5 \mathrm{~kg}$ & & & 1.57 & $1 \cdot 36,1 \cdot 81$ & $1 \cdot 49$ & $1 \cdot 29,1 \cdot 72$ & 1.50 & $1 \cdot 30,1 \cdot 73$ \\
\hline \multicolumn{9}{|c|}{ Household characteristics and care practices } \\
\hline Mother's age & & & & & $1 \cdot 00$ & $0.99,1 \cdot 01$ & $1 \cdot 00$ & $0.99,1.01$ \\
\hline \multicolumn{9}{|l|}{ Mother's BMI } \\
\hline Normal & & & & & Ref. & - & Ref. & - \\
\hline Underweight & & & & & $0 \cdot 67$ & $0.51,0.88$ & 0.67 & $0.50,0.88$ \\
\hline Overweight/obese & & & & & $1 \cdot 43$ & $1 \cdot 29,1.58$ & $1 \cdot 43$ & $1 \cdot 29,1 \cdot 58$ \\
\hline \multicolumn{9}{|l|}{ Mother's educational attainment } \\
\hline Higher education & & & & & Ref. & - & Ref. & - \\
\hline No education & & & & & $1 \cdot 19$ & $0 \cdot 80,1 \cdot 78$ & $1 \cdot 18$ & $0 \cdot 79,1 \cdot 77$ \\
\hline Elementary school & & & & & $0 \cdot 84$ & $0.70,1 \cdot 00$ & 0.83 & $0.69,0.99$ \\
\hline Secondary school & & & & & 0.92 & $0.80,1.06$ & 0.92 & $0.80,1.06$ \\
\hline No. of children & & & & & $1 \cdot 02$ & $0 \cdot 90,1 \cdot 14$ & $1 \cdot 02$ & $0 \cdot 90,1 \cdot 14$ \\
\hline Household size & & & & & 0.99 & $0.96,1.02$ & 0.99 & $0.96,1.02$ \\
\hline \multicolumn{9}{|l|}{ Family structure } \\
\hline Complete nuclear family & & & & & Ref. & - & Ref. & - \\
\hline Incomplete nuclear family & & & & & $1 \cdot 05$ & $0.79,1.39$ & 1.04 & $0 \cdot 79,1 \cdot 38$ \\
\hline Complete extended family & & & & & 1.04 & $0.90,1.20$ & 1.03 & $0.90,1 \cdot 19$ \\
\hline Incomplete extended family & & & & & $1 \cdot 19$ & $1 \cdot 00,1 \cdot 42$ & $1 \cdot 18$ & $0.99,1.41$ \\
\hline \multicolumn{9}{|l|}{ Female head of household } \\
\hline No & & & & & Ref. & - & Ref. & - \\
\hline \multirow{2}{*}{\multicolumn{9}{|c|}{ Head of household employed (yes) }} \\
\hline & & & & & & & & \\
\hline No & & & & & Ref. & - & Ref. & - \\
\hline \multirow{2}{*}{\multicolumn{9}{|c|}{ Breast-fed (yes) }} \\
\hline & & & & & & & & \\
\hline No & & & & & Ref. & - & Ref. & - \\
\hline \multirow{2}{*}{\multicolumn{9}{|c|}{ Immunization complete }} \\
\hline & & & & & & & & \\
\hline No & & & & & Ref. & - & Ref. & - \\
\hline Yes & & & & & $1 \cdot 13$ & $0.95,1.33$ & $1 \cdot 12$ & $0.95,1.32$ \\
\hline
\end{tabular}




\begin{tabular}{|c|c|c|c|c|c|c|c|c|}
\hline & \multicolumn{2}{|c|}{ Model 1} & \multicolumn{2}{|c|}{ Model 2} & \multicolumn{2}{|c|}{ Model 3} & \multicolumn{2}{|c|}{ Model 4} \\
\hline & PR & $95 \% \mathrm{Cl}$ & PR & $95 \% \mathrm{Cl}$ & PR & $95 \% \mathrm{Cl}$ & PR & $95 \% \mathrm{Cl}$ \\
\hline \multicolumn{9}{|l|}{ Health insurance } \\
\hline Uninsured & & & & & Ref. & - & Ref. & - \\
\hline Insured & & & & & 0.99 & $0 \cdot 89,1 \cdot 10$ & 0.99 & $0 \cdot 89,1 \cdot 10$ \\
\hline \multicolumn{9}{|l|}{ Contextual characteristics } \\
\hline \multicolumn{9}{|l|}{ Access to water } \\
\hline No & & & & & & & Ref. & - \\
\hline \multirow{2}{*}{\multicolumn{9}{|c|}{ Access to sanitation }} \\
\hline & & & & & & & & \\
\hline No & & & & & & & Ref. & - \\
\hline Yes & & & & & & & 0.94 & $0 \cdot 78,1 \cdot 14$ \\
\hline Urban & & & & & & & $0 \cdot 83$ & $0.71,0.98$ \\
\hline \multicolumn{9}{|l|}{ Community-level characteristics* } \\
\hline Women with high school completed (\%) & & & & & & & $1 \cdot 00$ & $1 \cdot 00,1 \cdot 00$ \\
\hline Men with high school completed (\%) & & & & & & & $1 \cdot 00$ & $1 \cdot 00,1 \cdot 01$ \\
\hline Community participation (\%) & & & & & & & $1 \cdot 03$ & $0.98,1.08$ \\
\hline Poverty (\%) & & & & & & & $1 \cdot 00$ & $1.00,1.00$ \\
\hline Women's employment $15-64$ years old (\%) & & & & & & & $1 \cdot 00$ & $1 \cdot 00,1 \cdot 00$ \\
\hline Men's employment $15-64$ years old (\%) & & & & & & & $1 \cdot 00$ & $1 \cdot 00,1 \cdot 00$ \\
\hline Female head of household (\%) & & & & & & & $1 \cdot 00$ & $1 \cdot 00,1.01$ \\
\hline Variance and covariance within household & 0.00 & 0.00 & 0.00 & 0.00 & 0.00 & 0.00 & $0 \cdot 00$ & 0.00 \\
\hline Variance and covariance within census sectors & 0.00 & 0.00 & 0.00 & 0.00 & 0.00 & 0.00 & 0.00 & 0.00 \\
\hline No. of households & 5942 & & & & & & & \\
\hline No. of census sectors & 1125 & & & & & & & \\
\hline 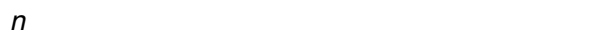 & 6963 & & & & & & & \\
\hline
\end{tabular}

PR, prevalence ratio; Ref., referent category.

All estimates are conditional on random effects.

At the census-sector level. 
Table 5 Hierarchical three-level Poisson regression models predicting overweight of children and adolescents aged 5-17 years, 2005 Colombian Demographic and Health Survey

\begin{tabular}{|c|c|c|c|c|c|c|c|c|}
\hline & \multicolumn{2}{|c|}{ Model 1} & \multicolumn{2}{|c|}{ Model 2} & \multicolumn{2}{|c|}{ Model 3} & \multicolumn{2}{|c|}{ Model 4} \\
\hline & PR & $95 \% \mathrm{Cl}$ & PR & $95 \% \mathrm{Cl}$ & PR & $95 \% \mathrm{Cl}$ & PR & $95 \% \mathrm{Cl}$ \\
\hline \multicolumn{9}{|l|}{ Wealth index } \\
\hline 1st quintile & Ref. & - & Ref. & - & Ref. & - & Ref. & - \\
\hline 2nd quintile & $1 \cdot 36$ & $1 \cdot 20,1.54$ & $1 \cdot 32$ & $1 \cdot 16,1 \cdot 49$ & $1 \cdot 1$ & $0.96,1.25$ & $1 \cdot 05$ & $0.91,1 \cdot 23$ \\
\hline 3rd quintile & $1 \cdot 81$ & $1 \cdot 60,2 \cdot 05$ & $1 \cdot 72$ & $1.52,1.95$ & $1 \cdot 31$ & $1 \cdot 15,1.49$ & $1 \cdot 23$ & $1 \cdot 05,1 \cdot 46$ \\
\hline 4th quintile & $2 \cdot 26$ & $1 \cdot 99,2 \cdot 56$ & $2 \cdot 12$ & $1 \cdot 87,2 \cdot 41$ & 1.52 & $1 \cdot 32,1 \cdot 74$ & $1 \cdot 42$ & $1 \cdot 19,1 \cdot 69$ \\
\hline 5th quintile & $2 \cdot 77$ & $2 \cdot 43,3 \cdot 16$ & $2 \cdot 58$ & $2 \cdot 26,2 \cdot 95$ & $1 \cdot 75$ & $1 \cdot 51,2 \cdot 04$ & $1 \cdot 63$ & $1 \cdot 35,1 \cdot 97$ \\
\hline \multicolumn{9}{|c|}{ Child health and demographic characteristics } \\
\hline Age & & & 0.98 & $0.97,0.99$ & 0.97 & $0.95,0.98$ & 0.97 & $0.95,0.98$ \\
\hline \multicolumn{9}{|l|}{ Sex } \\
\hline Female & & & Ref. & - & Ref. & - & Ref. & - \\
\hline Male & & & 0.91 & $0.85,0.98$ & 0.92 & $0.86,0.99$ & 0.92 & $0.86,0.99$ \\
\hline Birth order & & & 0.94 & $0.92,0.96$ & 0.96 & $0.92,1.01$ & 0.96 & $0.92,1.01$ \\
\hline \multicolumn{9}{|l|}{ Household characteristics } \\
\hline Mother's age & & & & & 1.01 & $1.01,1.02$ & $1 \cdot 01$ & $1 \cdot 01,1.02$ \\
\hline \multicolumn{9}{|l|}{ Mother's BMI } \\
\hline Normal & & & & & Ref. & - & Ref. & - \\
\hline Underweight & & & & & 0.43 & $0.27,0.69$ & 0.43 & $0.27,0.69$ \\
\hline Overweight/obese & & & & & $2 \cdot 17$ & $2 \cdot 01,2 \cdot 34$ & $2 \cdot 17$ & $2 \cdot 00,2 \cdot 34$ \\
\hline \multicolumn{9}{|l|}{ Mother's educational attainment } \\
\hline Higher education & & & & & Ref. & - & Ref. & - \\
\hline No education & & & & & $0 \cdot 87$ & $0 \cdot 69,1 \cdot 11$ & $0 \cdot 88$ & $0 \cdot 69,1 \cdot 12$ \\
\hline Elementary school & & & & & 0.84 & $0.75,0.95$ & $0 \cdot 85$ & $0.76,0.96$ \\
\hline Secondary school & & & & & 0.87 & $0.79,0.97$ & $0 \cdot 87$ & $0.79,0.97$ \\
\hline No. of children & & & & & 0.93 & $0.89,0.97$ & 0.93 & $0.89,0.98$ \\
\hline Household size & & & & & 0.93 & $0.91,0.95$ & 0.93 & $0.91,0.95$ \\
\hline \multicolumn{9}{|l|}{ Family structure } \\
\hline Complete nuclear family & & & & & Ref. & _- & Ref. & _- \\
\hline Incomplete nuclear family & & & & & 0.92 & $0.78,1.09$ & 0.92 & $0.78,1.09$ \\
\hline Complete extended family & & & & & $1 \cdot 16$ & $1 \cdot 05,1 \cdot 28$ & $1 \cdot 16$ & $1 \cdot 05,1 \cdot 28$ \\
\hline Incomplete extended family & & & & & 1.07 & $0.94,1.22$ & 1.07 & $0.94,1.22$ \\
\hline \multicolumn{9}{|l|}{ Female head of household } \\
\hline No & & & & & Ref. & - & Ref. & - \\
\hline \multirow{2}{*}{\multicolumn{9}{|c|}{ Head of household employed }} \\
\hline & & & & & & & & \\
\hline No & & & & & Ref. & - & Ref. & - \\
\hline Yes & & & & & $1 \cdot 10$ & $1 \cdot 00,1 \cdot 22$ & $1 \cdot 10$ & $1 \cdot 00,1 \cdot 22$ \\
\hline \multicolumn{9}{|l|}{ Health insurance } \\
\hline Uninsured & & & & & Ref. & - & Ref. & - \\
\hline Insured & & & & & $1 \cdot 04$ & $0 \cdot 96,1 \cdot 13$ & 1.04 & $0 \cdot 96,1 \cdot 13$ \\
\hline \multicolumn{9}{|l|}{ Contextual characteristics } \\
\hline \multicolumn{9}{|l|}{ Access to water } \\
\hline No & & & & & & & Ref. & - \\
\hline Yes & & & & & & & 0.93 & $0.82,1.06$ \\
\hline \multicolumn{9}{|l|}{ Access to sanitation } \\
\hline No & & & & & & & Ref. & - \\
\hline Yes & & & & & & & $1 \cdot 06$ & $0.91,1.22$ \\
\hline Urban & & & & & & & $1 \cdot 07$ & $0.94,1.22$ \\
\hline
\end{tabular}


inequalities in both children and adolescents. The study benefits from robustly collected data in a large sample covering a wide range of socio-economic data, in addition to the core anthropometrics. The survey methodology has been replicated elsewhere, allowing comparison with other countries or other survey dates in Colombia in subsequent studies. Also, a rich set of variables was used at the individual, household and contextual levels in order to explain malnutrition inequalities.

Although we have been able to assess some of the factors underlying wealth-related nutritional inequalities, it is not possible to make causal inferences from crosssectional data. In addition, our study lacked data on other likely determinants of childhood nutritional status such as dietary patterns and community recreational space. Nevertheless, our findings suggest several novel hypotheses which could be explored in subsequent cohort or interventional studies, such as whether promoting community participation or better support for female heads of household could reduce the prevalence of childhood overweight.

\section{Meaning of the study}

Our findings suggest several opportunities both for identification of children at risk of malnutrition and for intervention. Specifically, children from poorer households or with poorly educated mothers are at higher risk of stunting, and children from wealthier households or with overweight mothers are at higher risk of overweight. For both outcomes, it would appear that focusing attention on household factors may be the most promising route initially to reduce the burden of stunting or overweight and associated inequalities, since it is here that the greatest explanatory power lies.

Regarding childhood stunting, boosting household incomes, increasing access to potable water and sanitation and supporting community participation may offer effective means to protect against this outcome and reduce inequalities. These actions are needed both in urban and rural areas as we have shown that poor children are not necessarily protected from stunting if living in an urban area.

Regarding childhood overweight, Davison and Birch ${ }^{(26)}$ describe a 'cyclical relationship' between parental weight status, parenting/feeding practices and children's nutritional status. In early stages of the nutrition transition, high-income individuals are more likely to have diets rich in meat, fat and sugars $^{(12)}$. Thus, one possible explanation for the association between mother's BMI and inequalities in overweight is that children living in richer households have parents with caring practices and eating behaviours that promote more energy intake and more sedentary behaviours than those living in poor households. However, being poor or living in rural areas is not necessarily a protective factor for overweight ${ }^{(41)}$. This finding poses a particular challenge for policy makers, who must eradicate hunger and 
undernutrition among the poor while preventing the emergence of overweight with all its health consequences in terms of chronic diseases.

Close attention to these social determinants may allow Colombia and other countries at a similar stage of development to tackle the problem of childhood undernutrition effectively without increasing rates of overnutrition, particularly among disadvantaged children where the risk of a double burden of malnutrition and exacerbation of health inequalities is high.

\section{Acknowledgements}

Source of funding: The Demographic and Health Survey of Colombia 2005 was funded by the US Agency for International Development (USAID), the United Nations Population Fund (UNFPA), the Colombian Institute of Family Welfare (ICBF) and Colombia's Ministry of Health and Social Protection. The present study was supported by a research grant from Universidad de los Andes. Conflicts of interest: There no conflicts of interest, financial or of any other kind, for the authors of this paper. Authors' contributions: S.G. and O.L.S. planned the paper and wrote the first draft. I.F. reviewed the paper and contributed to the final version, particularly the interpretation and discussion of results. T.V. contributed to data analysis as well as to the final version of the paper.

\section{References}

1. Fotso JC \& Kuate-Defo B (2005) Socioeconomic inequalities in early childhood malnutrition and morbility: modification of the household-level effects by the community SES. Health Place 11, 205-225.

2. Menon P, Ruel MT \& Morris SS (2000) Socioeconomic Differentials in Child Stunting are Consistently Larger in Urban than in Rural Areas. Food and Nutrition Discussion Paper no. 97. Washington, DC: International Food Policy Research Institute.

3. Petrou S \& Kupek E (2010) Poverty and childhood undernutrition in developing countries: a multi-national cohort study. Soc Sci Med 71, 1366-1373.

4. Van de Poel E, Hosseinpoor AR, Speybroeck N et al. (2008) Socioeconomic inequality in malnutrition in developing countries. Bull World Health Organ 86, 241-320.

5. Martorell R, Kettel KL, Hughes ML et al. (2000) Overweight and obesity in preschool children from developing countries. Int J Obes Relat Metab Disord 24, 959-967.

6. Ruel MT \& Menon P (2002) Child feeding practices are associated with child nutritional status in Latin America: innovative uses of the demographic and health surveys. J Nutr 132, 1180-1187.

7. Smith LC, Ruel MT \& Ndiaye A (2004) Why is Child Malnutrition Lower in Urban than Rural Areas? Evidence from 36 Developing Countries. Food and Nutrition Discussion Paper no. 176. Washington, DC: International Food Policy Research Institute.

8. Iram U \& Butt MS (2004) Determinants of household food security: an empirical analysis for Pakistan. Int J Soc Econ 31, 753-766.
9. Wagstaff A, Bustreo F, Bryce J et al. (2004) Child health: reaching the poor. Am J Public Health 94, 726-736.

10. Monteiro CA, Bustreo F, Bryce J et al. (2004) Socioeconomic status and obesity in adult populations of developing countries: a review. Bull World Health Organ 82, 940-946.

11. McLaren L (2007) Socioeconomic status and obesity. Epidemiol Rev 29, 29-48.

12. Monteiro C, Conde WL, Lu B et al. (2004) Obesity and inequities in health in the developing world. Int $J$ Obes Relat Metab Disord 28, 1181-1186.

13. Popkin BM (2001) The nutrition transition and obesity in the developing world. J Nutr 131, issue 3, 871S-873S.

14. Uauy R, Kain J, Mericq V et al. (2008) Nutrition, child growth and chronic disease prevention. Ann Med 40, 11-20.

15. Alderman H, Hoddinott J \& Kinsey B (2006) Long term consequences of early childhood malnutrition. Oxford Econ Papers 58, 450-474.

16. Datar A, Sturm R \& Magnabosco JL (2004) Childhood obestity and academic performance: national study of kindergartners and first graders. Obes Res 12, 58-68.

17. Glewwe P, Jacoby HG \& King E (2001) Early childhood nutrition and academic achievement: a longitudinal analysis. J Public Econ 81, 345-368.

18. Jyoti D, Frongillo EAJ \& Jones S (2005) Food insecurity affects school children's academic performance, weight gain, and social skills. J Nutr 135, 2831-2839.

19. UNICEF (1998) The State of the World's Children 1998. New York: UNICEF.

20. Winicki J \& Jeminson K (2003) Food insecurity and hunger in the kindergarten classroom: its effect on learning and growth. Contemp Econ Policy 21, 145-157.

21. Profamilia \& ICF Macro (2010) Colombia Demographic and Health Survey 2010, Final Report. Bogota: Profamilia and ICF Macro.

22. Economic Commission for Latin America and the Caribbean (2010) Social Panorama of Latin America. Santiago: ECLAC.

23. Profamilia \& ICF Macro (2005) Cololmbia Demographic and Health Survey 2005, Final Report. Bogota: Profamilia and ICF Macro.

24. Sarmiento OL, Ramirez A, Samper B et al. (2012) Nutrition in Colombian pregnant women. Public Health Nutr (Eublication ahead of print version).

25. Mosley WH \& Chen LC (2003) An analytical framework for the study of child survival in developing countries. Bull World Health Organ 81, 140-145.

26. Davison KK \& Birch LL (2001) Weight status, parent reaction, and self-concept in five-year-old girls. Pediatrics 107, 46-53.

27. Humphrey J (2009) Child undernutrition, tropical enteropathy, toilets, and handwashing. Lancet 374, 1032-1035.

28. Wang Y \& Lobstein T (2006) Worldwide trends in childhood overweight and obesity. Int J Pediatr Obes 1, 11-25.

29. World Health Organization (2006) Child Growth Standards: Length/Height-for-Age, Weight-for-Age, Weight-for-Length, Weight-for-Height and Body Mass Index-for-Age: Methods and Development. Geneva: WHO.

30. De Onis M, Onyango A, Borghi E et al. (2007) Development of a WHO growth reference for school-aged children and adolescents. Bull World Health Organ 85 , 660-667.

31. Rutstein SO \& Johnson K (2004) The DHS Wealth Index. DHS Comparative Reports no. 6. Calverton, MD: ORC Macro.

32. Barros FC, Victora CG, Scherpbier RW et al. (2010) Health and nutrition of children: equity and social determinants. In Equity, Social Determinants and Public Health Programmes, pp. 49-75 [E Blas and AD Kurup, editors]. Geneva: WHO 
33. O'Donnell O, Doorslaer E, Wagstaff A et al. (2008) Analyzing Health Equity Using Household Survey Data: A Guide to Techniques and their Implementation. Washington, DC: World Bank.

34. Howe LDL, Hargreaves JR, Gabrysch SS et al. (2009) Is the wealth index a proxy for consumption expenditure? A systematic review. J Epidemiol Community Health $\mathbf{6 3}$, 871-877.

35. Kuate-Defo B (2005) Measuring socioeconomic status in health research in developing countries: should we be focusing on households, communities or both? Soc Indic Res 72, 189-237.

36. Houweling T, Kunst J \& Mackenbach JP (2003) Measuring health inequality among children in developing countries: does the choice of the indicator of economic status matter? Int J Equity Health 2, 8-17.

37. Kennedy G, Nantel G, Brouwer ID et al. (2006) Does living in an urban environment confer advantages for childhood nutritional status? Analysis of disparities in nutritional status by wealth and residence in Angola, Central African Republic and Senegal. Public Health Nutr 9, 187-193.

38. McDonald C, Baylin A, Arsenault J et al. (2009) Overweight is more prevalent than stunting and is associated with socioeconomic status, maternal obesity, and a snacking dietary pattern in school children from Bogotá, Colombia. J Nutr 139, 370-376.

39. Ruel MT, Levin CE, Armar-Klemesu M et al. (1999) Good care practices can mitigate the negative effects of poverty and low maternal schooling on children's nutritional status: evidence from Accra. World Dev 27, 1993-2009.

40. Cole T (2000) Secular trends in growth. Proc Nutr Soc 59 , 317-324.

41. Forde I, Chandola T, Garcia S et al. (2011) The impact of cash transfers to poor women in Colombia on BMI and obesity: prospective cohort study. Int J Obes (Lond) (Epublication ahead of print version). 